\title{
The identification of salicylates as normal constituents of serum: a link between diet and health?
}

\author{
John R Paterson, Claire Blacklock, Graham Campbell, David Wiles, James R Lawrence
}

\begin{abstract}
Aim-To examine sera for the presence of salicylic acid and 2,3- and 2,5-dihydroxybenzoic acids (2,3- and 2,5-DHBA), in individuals not taking salicylate drugs.

Methods-Extracts of acidified serum samples were analysed by high performance liquid chromatography with electrochemical detection. The chromatographic conditions were altered, and the retention times of the unknown compounds compared against authentic salicylic acid, 2,3-DHBA, and 2,5-DHBA. Serum samples (some spiked with salicylic acid) were incubated with salicylate hydroxylase and analyses undertaken. An extract of acidified serum was derivatised using N-methyl-Ntrimethylsilyltrifluoroacetamide and the salicylic acid derivative identified by gas chromatography-mass spectrometry.

Results-Salicylic acid, 2,3-DHBA, and 2,5-DHBA were identified as being normal constituents of serum.

Conclusions-Salicylic acid, 2,3-DHBA, and 2,5-DHBA possess anti-inflammatory properties. The finding that these compounds are present as normal constituents of serum, possibly arising from diet, raises important questions as to their role in the promotion of health.

(f Clin Pathol 1998;51:502-505)
\end{abstract}

Keywords: salicylic acid; 2,3- and

2,5-dihydroxybenzoic acids; normal serum constituents; diet

Dumfries and Galloway Royal Infirmary, Dumfries, UK:

Area Department of Biochemistry

J R Paterson

C Blacklock

G Campbell

D Wiles

Department of

Medicine

J R Lawrence

Correspondence to: Dr John R Paterson, Area Department of Biochemistry, Dumfries and Galloway Royal Infirmary, Bankend Road, Dumfries DG1 4AP, UK.

Accepted for publication 13 January 1998 of the formation and action of salicylic acid. Salicylic acid has also been found to induce cell cycle arrest and apoptosis in cultured colorectal tumour cells, ${ }^{7}$ indicating that the chemopreven-
Salicylates, initially obtained from the bark of also in preventing inflammatory drugs. ${ }^{3}$ Aspirin is rapidly hydrolysed to salicylic acid in vivo, ${ }^{5}$ and its anti- tive property of aspirin may act through salicylic acid formation as well.

While investigating the use of low dose aspirin as an aromatic probe to measure hydroxyl free radicals (by assessing the hydroxylation of salicylic acid, with resulting formation of 2,3and 2,5-dihydroxybenzoic acid (2,3- and 2,5DHBA)), we observed the presence of substances which had identical retention times to salicylic acid, 2,3-DHBA, and 2,5-DHBA in serum extracts from subjects not taking aspirin. After excluding the possibility of contamination, we investigated whether these substances were authentic salicylic acid, 2,3-DHBA, and 2,5-DHBA.

\section{Methods}

BLOOD SAMPLES

Blood samples were obtained from healthy volunteers who were not taking any drugs, nor had they been using other preparations which contain salicylates, for example mouthwashes. Whole blood was allowed to coagulate before separating the serum by centrifugation $(2000 \mathrm{~g}$ for 10 minutes). Aliquots of serum were stored at $-28^{\circ} \mathrm{C}$.

SALICYLATE EXTRACTION AND HPLC ANALYSIS Ethylenediaminetetra-acetic acid (EDTA; final serum concentration $100 \mu \mathrm{mol} /$ litre) was added to portions of serum $(0.5 \mathrm{ml})$ which were then acidified to $\mathrm{pH} 2.0$ by the addition of $\mathrm{HCl}(1.0$ $\mathrm{mol} /$ litre $)$, and ethyl acetate $(2.0 \mathrm{ml})$ then added. The extraction tubes were shaken for 15 minutes, centrifuged at $2000 \mathrm{~g}$, and the organic phase removed and evaporated to dryness at $70^{\circ} \mathrm{C}$ under oxygen-free nitrogen. The extraction process was repeated and the combined extracts reconstituted in high performance liquid chromatography (HPLC) mobile phase$0.50 \mathrm{ml}$, citrate buffer $(0.03 \mathrm{~mol} /$ litre $)$ brought to $\mathrm{pH} 4.0$ with the addition of glacial acetic acid, methanol (29.6\% vol/vol), and EDTA (100 $\mu \mathrm{mol} /$ litre). A Jasco (Great Dunmow, Essex, UK) PU-980 HPLC pump and LG 980-02 ternary gradient unit were used to deliver mobile phase at $1.0 \mathrm{ml} / \mathrm{min}$ through an Apex ODS $5 \mu \mathrm{m}$ column (Jones Chromatography, Hengoed, Shropshire, UK). Amperometric detection was carried out using an Antec Decade detector (Presearch, Hitchin, Herts, UK) with an oxidising potential (Eox) of +1.1 V. Fifty microlitres of the reconstituted extract were injected with a run time of 30 minutes. Chromatographic conditions were altered by reducing the methanol concentration and by varying the Eox of the electrochemical detec- 

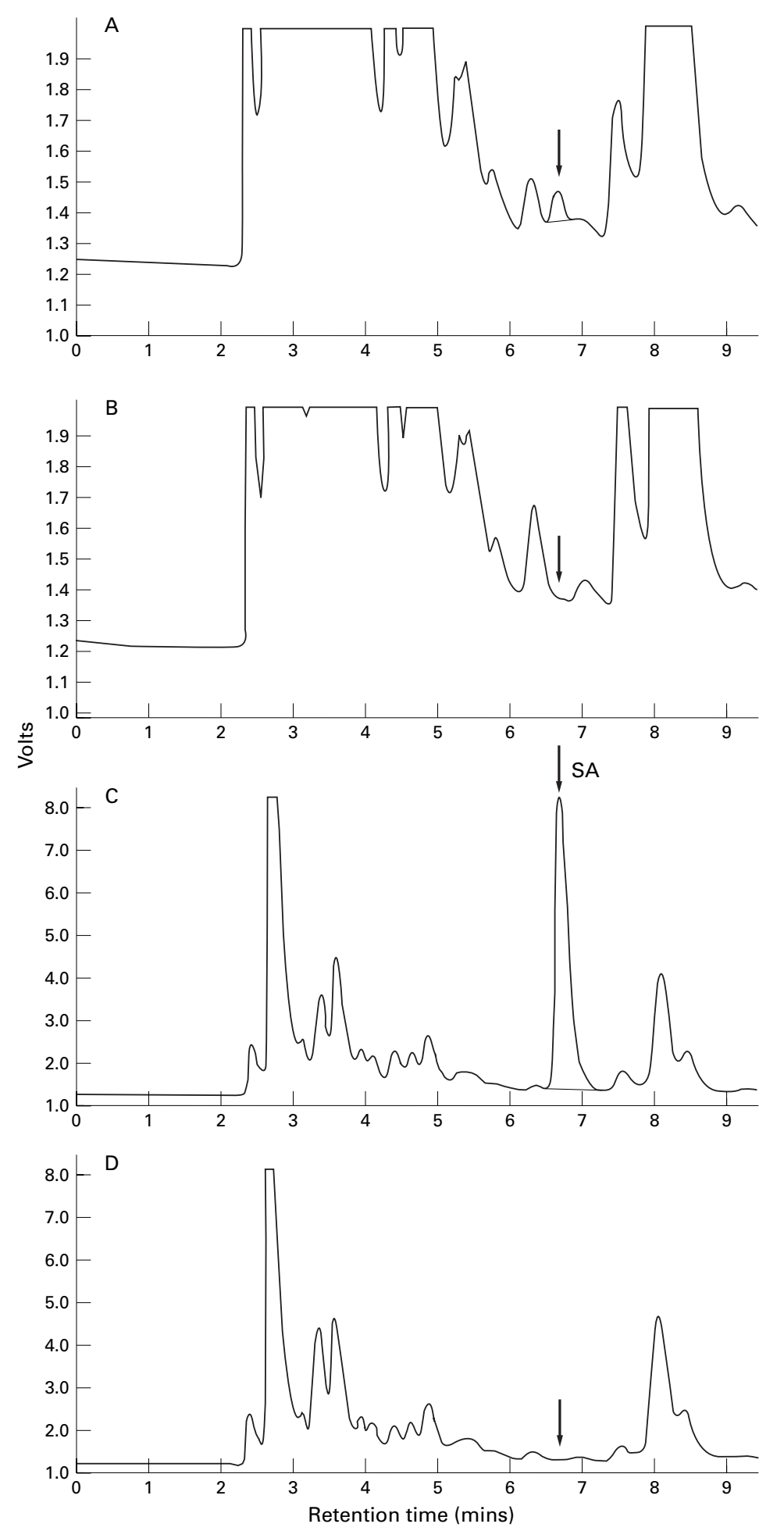

Figure 1 HPLC chromatograms of extracts of reaction mixtures: $(A)$ blank serum and NADH; (B) blank serum, NADH, and salicylate hydroxylase; (C) blank serum, NADH, and salicylic acid; (D) blank serum, $N A D H$, salicylic acid, and salicylate hydroxylase.

tor. To carry out chromatography of 2,3DHBA and 2,5-DHBA, the Eox was $+0.65 \mathrm{~V}$ and gradient elution was used: $0-6$ minutes with $100 \%$ citrate buffer ( $0.03 \mathrm{~mol} / \mathrm{litre}), \mathrm{pH}$ 5.25 (by addition of glacial acetic acid), and 6-15 minutes in the same mobile phase with methanol $28.6 \%$ vol/vol. Chromatographic conditions were altered by changing the mobile phase to $\mathrm{pH} 4.75$.
Table 1 Effect of mobile phase methanol concentration (vol/vol) on the retention time ( $t$ ) of aqueous standard ( $S A, 1$ umolllitre), serum spiked with SA (1 1 moll/litre), and blank serum

\begin{tabular}{|c|c|c|c|}
\hline $\begin{array}{l}\text { Methanol } \\
(\% \\
\text { vol/vol) }\end{array}$ & $S A(t, m i n)$ & $\begin{array}{l}\text { Serum spiked } \\
\text { with } S A \\
\left(t_{r}, \text { min }\right)\end{array}$ & $\begin{array}{l}\text { Blank serum: } \\
\text { unknown substance } \\
\left(t_{r}, \text { min }\right)\end{array}$ \\
\hline 20.0 & 9.05 & 9.00 & 8.95 \\
\hline 20.6 & 8.79 & 8.76 & 8.79 \\
\hline 23.0 & 8.14 & 8.10 & 8.09 \\
\hline 28.6 & 7.30 & 7.26 & 7.22 \\
\hline
\end{tabular}

INCUBATION OF SERUM WITH SALICYLATE HYDROXYLASE

Portions of serum $(0.5 \mathrm{ml})$ from five different subjects were incubated with reduced nicotinamide adenine dinucleotide $(\beta \mathrm{NADH} ; 146$ $\mu \mathrm{mol} /$ litre $)$ and salicylate hydroxylase $(0.48$ units, obtained from Pseudomonas sp; Sigma, Poole, Dorset, UK) in a final volume of $1.5 \mathrm{ml}$ with phosphate buffer (0.03 mol/litre), $\mathrm{pH}$ 7.62. Control reaction mixtures contained no salicylate hydroxylase or were spiked with salicylic acid (final concentrations $5 \mu \mathrm{mol} /$ litre). Reaction mixtures were incubated at $30^{\circ} \mathrm{C}$ in a shaking waterbath for 15 minutes before extraction as described above.

\section{SERUM EXTRACTION, DERIVATISATION, AND} ANALYSIS BY GC-MS

To an aqueous solution of salicylic acid (10 $\mu \mathrm{mol} / \mathrm{litre}, 300 \mu \mathrm{l}$ volume) was added $\mathrm{HCl}$ (100 $\mu \mathrm{l}, 1.0 \mathrm{~mol} /$ litre) and the resultant solution extracted twice with ethyl acetate $(0.5 \mathrm{ml})$. The combined extracts were evaporated to dryness at $70^{\circ} \mathrm{C}$ under oxygen-free nitrogen and $\mathrm{N}$-methyl-N-trimethylsilyltrifluoroacetamide (MSTFA; $300 \mu \mathrm{l}$ ) added. The reaction mixture was vortexed for 30 seconds and then heated at $70^{\circ} \mathrm{C}$ for 20 minutes to prepare the trimethylsilyl (TMS) derivative of salicylic acid.

To serum $(7.5 \mathrm{ml})$ from one individual was added EDTA (final concentration $100 \mu \mathrm{mol} /$ litre $)$ and $\mathrm{HCl}(1.0 \mathrm{~mol} /$ litre to bring to $\mathrm{pH} 2.0)$ and the resultant mixture extracted twice with ethyl acetate $(15 \mathrm{ml})$. The combined extracts were evaporated to dryness at $70^{\circ} \mathrm{C}$ under oxygen-free nitrogen and MSTFA $(50 \mu \mathrm{l})$ added, the reaction mixture then treated in the same way as the salicylic acid standard above.

The derivatised extracts of salicylic acid and serum were transferred to sample vials for gas chromatography-mass spectrometry (GCMS) analysis (Fisons, Manchester, UK: MD 800 mass spectrometer, GC 8000 series, and AS 800 autosampler, equipped with a $30 \mathrm{~m}$, $0.25 \mathrm{~mm}$ DB-5 capillary column). A $1 \mu \mathrm{l} \mathrm{sam-}$ ple was injected using a splitless injection port and a helium flow rate of $1 \mathrm{ml} / \mathrm{min}$. The GC column temperature was initially set at $55^{\circ} \mathrm{C}$ for one minute, increasing by $30^{\circ} \mathrm{C}$ a minute to $265^{\circ} \mathrm{C}$. The mass spectrometer was set at an electron energy of $70 \mathrm{eV}$ and full scan mode (40.00 to 400.0 mass range).

\section{Results}

Chromatography of the extracted sera from six individuals revealed the presence of an unknown substance, in each case having a similar retention time $\left(t_{r}\right)$ to that of authentic salicylic 


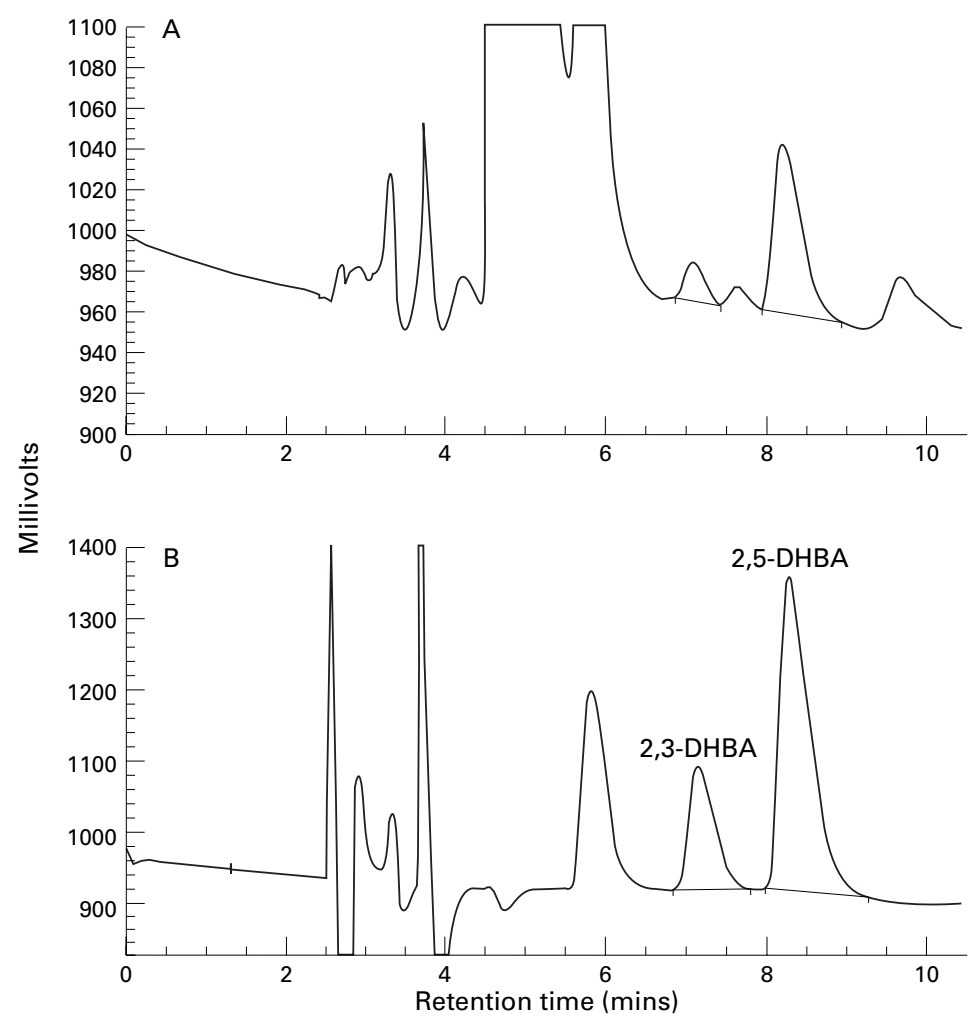

Figure 2 HPLC chromatograms of an extract of $(A)$ blank serum and $(B)$ an aqueous mixture of 2,3- and 2,5-DHBA.

acid (fig 1A, typical chromatogram). When the methanol concentration of the mobile phase was reduced, the $t_{r}$ of the unknown substance increased and paralleled that of salicylic acid (table 1). Contamination and carryover were excluded by injecting the extract of a reaction mixture minus serum, and mobile phase. The electrochemical response of the unknown substance was obtained by changing the Eox and comparing this change to that of authentic salicylic acid. Baseline data were collected with an Eox of $+1.1 \mathrm{~V}$ and the percentage change of the response from this setting recorded at Eox values of $+1.15,+1.20$. and $+1.25 \mathrm{~V}$ for both the unknown substance and salicylic acid. Values of $252 \%, 697 \%$, and $301 \%$ were obtained for salicylic acid, while for the unknown, values of $220 \%, 640 \%$, and $240 \%$ were determined, a similar change in response being observed for the unknown substance and salicylic acid.

Chromatography of the extracted sera (fig 2) also revealed the presence of unknown substances with similar $t_{r}$ values to 2,3-DHBA and 2,5-DHBA. When the mobile phase $\mathrm{pH}$ was changed to 4.75 , the $t_{r}$ values of the unknown substances changed in an identical fashion to those of 2,3-DHBA and 2,5-DHBA (table 2).

When serum (some spiked with salicylic acid) was incubated in the absence and presence of salicylate hydroxylase, the chromatograms (fig 1) showed that the unknown substance with an identical retention time to that of salicylic acid disappeared when incubated in the presence of salicylate hydroxylase and NADH. A serum sample spiked with salicylic acid behaved similarly, indicating that the unknown substance was salicylic acid. Similar
Table 2 Effect of changing the mobile phase $\mathrm{pH}$ on the tetention time $(t)$ of unknown substances present in serum and 2,3- and 2,5-DHBA

\begin{tabular}{|c|c|c|c|c|}
\hline $\begin{array}{l}\text { Mobile } \\
\text { phase } \\
\text { pH }\end{array}$ & $\begin{array}{l}\text { Aqueous } \\
\text { standard } \\
2,3-D H B A \\
\left(t_{r}, \text { min }\right)\end{array}$ & $\begin{array}{l}\text { Unknown } \\
\text { substance } \\
\left(t_{r}, \text { min }\right)\end{array}$ & $\begin{array}{l}\text { Aqueous } \\
\text { standard } \\
2,5-D H B A \\
\left(t_{r}, \text { min }\right)\end{array}$ & $\begin{array}{l}\text { Unknown } \\
\text { substance } \\
\left(t_{r}, \text { min }\right)\end{array}$ \\
\hline 5.25 & 8.00 & 8.01 & 9.39 & 9.42 \\
\hline 4.75 & 8.30 & 8.29 & 9.05 & 9.05 \\
\hline
\end{tabular}

results were obtained for all five individuals investigated.

The $\mathrm{TMS}_{2}$ derivative of salicylic acid was found to have a $t_{r}$ of 6.461 minutes when analysed by GC-MS. Examination of the chromatogram obtained from the derivatised serum extract revealed substances with overlapping $t_{r}$ values of 6.421 and 6.471 minutes. With GC-MS analysis of MSTFA in hexane, compounds with $\mathrm{t}_{\mathrm{r}}$ values of $6.431,6.481$, and 6.522 minutes, respectively, were found. Total ion chromatograms showed the presence of an abundant ion at $\mathrm{m} / \mathrm{z} 267$ in the serum extract and in MSTFA; however, the best fit for the fragmentation pattern at 6.441 minutes in the serum extract was $\mathrm{TMS}_{2}$ salicylic acid $\left(\mathrm{TMS}_{2}\right.$ salicylic acid molecular ion minus methyl). Various siloxane compounds best fitted the MSTFA total ion chromatogram.

\section{Discussion}

We have found three different salicylatessalicylic acid, 2,3-DHBA, and 2,5-DHBA-to be present as normal constituents of serum. The previously unknown substances we had observed in chromatograms behaved in an identical fashion to the authentic salicylate compounds when chromatographic conditions were changed. Although similar changes in chromatographic parameters between an unknown substance and an authentic compound are not absolute proof that they are identical, the similarities described above, supported by the evidence obtained from the salicylate hydroxylase and GC-MS experiments, indicates to us that salicylic acid is present as a normal constituent of serum in "aspirin-free" individuals. The serum analysis was difficult because salicylic acid was present in low concentration and because of potential interference from MSTFA in the GC-MS experiments. There is, however, no serum sample analysed so far $(n=60)$ that has not contained salicylic acid. Examination of the chromatograms of blank serum or plasma from published HPLC methods of salicylic acid analysis reveals also that an unknown substance is present with a $t_{r}$ similar to salicylic acid, but which is not commented upon in the respective papers. ${ }^{8}{ }^{9} \mathrm{In}$ addition, Ruffin et al reported salicylic acid in the plasma from 17 of 53 subjects at baseline, before aspirin intake, in a study examining the effect of aspirin on mucosal prostaglandins. ${ }^{10}$ No information was given as to how they identified the compound as being salicylic acid.

We are currently developing a method for quantitation of the naturally occurring salicylates and have observed significant differences between individuals. It is possible that diet is the source of salicylic acid since it is 
found in fruits, berries, vegetables, herbs, and spices. ${ }^{11}$ Salicylic acid is metabolised in vivo to various compounds, including 2,3-DHBA and $2,5-\mathrm{DHBA},{ }^{12}$ although these salicylates may also be present in our diet since they are known to be present in wine. ${ }^{13}$ Recently, from the measurement of salicylic acid in urine, the daily dietary intake of salicylic acid was estimated to be of the order of a few milligrams. ${ }^{14}$ The authors considered this intake to be too low to affect the risk of coronary heart disease or colon cancer "even if most of this would be in the form of acetylsalicylate" (aspirin). However, the dose of aspirin required to help prevent colorectal cancer is unknown, as is the minimum dose of aspirin effective in protecting the vasculature. The anti-platelet effect of aspirin is the major reason for prescribing the drug in cardiovascular disease, although recent work suggests that the anti-inflammatory action may also be important. ${ }^{15}$ It is possible that the antiinflammatory action and chemopreventive action in colorectal cancer occurs by the same mechanism. In inflammation ${ }^{16}$ and colorectal cancer, ${ }^{17}$ cyclooxygenase (COX) 2 , an enzyme catalysing the formation of prostanoid compounds, is induced by various stimuli including cytokines and growth factors, unlike the constitutively expressed COX 1 which is found in platelets. Aspirin is more potent than salicylate at inhibiting prostaglandin synthesis in vitro through its effects on COX activity, but the two compounds are considered to be equipotent as anti-inflammatory agents. ${ }^{6}$ In vivo, aspirin probably acts as an anti-inflammatory prodrug, the active component being salicylic acid. Salicylic acid has been shown to inhibit the induction of COX activity by interleukin $-1,{ }^{18}$ an effect observed at nanomolar concentrations of salicylic acid. 2,3- and 2,5-DHBA have also been shown to inhibit COX activity, to modulate cytokine production, and inhibit the formation of prostaglandin E2 in vitro. ${ }^{19-21}$ We believe that our finding of salicylic acid, 2,3-DHBA, and 2,5-DHBA as normal constituents of serum may provide a link between diet and the prevention of colorectal cancer and atherosclerosis. A diet which is rich in fruit and vegetables helps prevent colorectal cancer and atherosclerosis, and although various dietary components have been examined as possible candidates to explain the benefits of such a diet, no individual responsible component has been identified, especially in the prevention of cancer. ${ }^{22}$ We are currently investigating the relation between diet and serum salicylate concentrations in "aspirin-free" patients.
We thank the late Mr G C L Willock, Dumfries and Galloway Acute and Maternity Hospitals NHS Trust and the Chest, Heart and Stroke Association (Scotland) for financial assistance, and acknowledge the valuable advice of Dr A B Graham, Strathclyde University, Glasgow.

1 Fairley P. The aspirin story. In: The conquest of pain. London: Michael Joseph, 1978:124-67.

2 Antiplatelet Trialists Collaboration. Collaborative overview of randomised trials of antiplatelet treatment. I. Prevention of death, myocardial infarction, and stroke by prolonged antiplatelet therapy in various categories of patients. $B M F$ 1994;308:81-106.

3 Paganini-Hill A. Aspirin and the prevention of colorectal cancer: a review of the evidence. Semin Surg Oncol 1994;10:158-64.

4 Marcus AJ. Aspirin as the prophylaxis against colorectal cancer. $N$ Engl f Med 1995;333:656-8.

5 Davison C. Salicylate metabolism in man. Ann N Y Acad Sci 1971;179:249-68.

6 Higgs GA, Salmon JA, Henderson B, et al. Pharmacokinetics of aspirin and salicylate in relation to inhibition of arachidonate cyclooxygenase and antiinflammatory activity. Proc Natl Acad Sci USA 1987;84:1417-20.

7 Elder DJE, Hague A, Hicks DJ, et al. Differential growth inhibition by the aspirin metabolite salicylate in human colorectal tumour cell lines: enhanced apoptosis in carcinoma and in vitro-transformed adenoma relative to adenoma cell lines. Cancer Res 1996;56:2273-6.

8 Vree TB, van Ewijk-Beneken Kolmer EWJ, Verwey-van Wissen CPWGM, et al. Direct gradient reversed-phase high-performance liquid chromatographic determination of salicylic acid, with the corresponding glycine and glucuronide conjugates in human plasma and urine. $\mathcal{f}$ glucuronide conjugates in hum
Chromatogr B 1994;652:161-70.

9 Coudray C, Mangournet C, Bouhadjeb S, et al. Rapid highperformance liquid chromatographic assay for salicylic acid in plasma without solvent extraction. $\mathcal{F}$ Chromatogr Sci 1996;34:166-73.

10 Ruffin MT, Krishnan K, Rock CL, et al. Suppression of human colorectal mucosal prostaglandins: determining the lowest effective aspirin dose. I Natl Cancer Inst 1997;89: 1152-60.

11 Venema DP, Hollman PCH, Janssen KPLTM, et al. Determination of acetylsalicylic acid and salicylic acid in foods,
using HPLC with fluorescence detection. $\mathcal{7}$ Agric Food Chem 1996;44:1762-7.

12 Grootveld M, Halliwell B. 2,3-Dihydroxybenzoic acid is a product of human aspirin metabolism. Biochem Pharmacol 1988;37:271-80.

13 Muller CJ, Fugelsang KC. Take two glasses of wine and see me in the morning. Lancet 1994;343:1428-9.

14 Janssen KPLTM, Hollman PCH, Reichman E, et al. Urinary salicylate excretion in subjects eating a variety of Urinary salicylate excretion in subjects eating a variety of
diets shows that amounts of bioavailable salicylates in food are low. Am f Clin Nutr 1996;64:743-7.

15 Ridker PM, Cushman M, Stampfer MJ, et al. Inflammation, aspirin, and the risk of cardiovascular disease in apparently healthy men. $N$ Engl f Med 1997;336:973-9.

16 Williams CS, Dubois RN. Prostaglandin endoperoxide synthase: why two isoforms? Am $\mathcal{f}$ Physiol 1996;270 (Gastrointest Liver Physiol 33):G393-400.

17 Kargman SL, O’Neill GP, Vickers PJ, et al. Expression of prostaglandin $\mathrm{G} / \mathrm{H}$ synthase- 1 and -2 protein in human prostaglandin $\mathrm{G} / \mathrm{H}$ synthase-1 and -2 prote
colon cancer. Cancer Res 1995;55:2556-9.

$18 \mathrm{Wu} \mathrm{KW,} \mathrm{Sanduja} \mathrm{R,} \mathrm{Tsai} \mathrm{A-L,} \mathrm{et} \mathrm{al.} \mathrm{Aspirin} \mathrm{inhibits}$ interleukin 1-induced prostaglandin $\mathrm{H}$ synthase expression in cultured endothelial cells. Proc Natl Acad Sci USA 1991; 88:2384-7.

19 Flower RJ. Drugs which inhibit prostaglandin biosynthesis. Pharmacol Rev 1974;26:33-67.

20 Blackwell GJ, Flower RJ, Vane JR. Some characteristics of the prostaglandin synthesizing system in rabbit kidney the prostaglandin synthesizing system in rabbit kidn
microsomes. Biochim Biophys Acta 1975;398:178-90.

21 Haynes DR, Wright PFA, Gadd SJ, et al. Is aspirin a prodrug for antioxidant and cytokine-modulating oxymetabolites? Agents Actions 1993;39:49-58.

22 Greenberg ER, Sporn MB. Antioxidant vitamins, cancer and cardiovascular disease. N Engl f Med 1996;334;118990 . 